\title{
MEJORA PERSONAL E INSPIRACIÓN ARTÍSTICA EN EL ENTORNO NATURAL
}

\section{PERSONAL IMPROVEMENT AND INSPIRATION ART IN THE NATURAL ENVIRONMENT}

\author{
María Mónica Rubio Vega1. Universidad Católica San Antonio. Murcia, España. \\ mrubiovega@yahoo.es
}

Silvia Viñao Manzanera. Universidad Católica San Antonio. Murcia, España. silviavinao@gmail.com

\section{RESUMEN}

Con este texto, buscamos defender y divulgar los beneficios que aporta la naturaleza tanto al individuo como al artista; en este caso, mostrando en concreto cómo incide en su inspiración. La primera parte es un acercamiento al enfoque científico que identifica beneficios inmateriales en el contacto con el entorno natural, lo que habla del nexo entre el ser humano y la naturaleza. En la segunda, estudiaremos los modos de aproximación del artista a la naturaleza, poniendo como caso práctico las experiencias de la artista y pintora Silvia Viñao. Para terminar, completaremos el artículo exponiendo cómo los valores ecológicos se transmiten al espectador por medio de la obra de arte.

PALABRAS CLAVE: beneficios de la naturaleza, arte, desarrollo humano, ecología, valores, paisaje.

\section{ABSTRACT}

With this text, we pursue defend and promote the benefits that nature provides both the individual and the artist; in this case, showing in particular how this affects their inspiration. The first part is an approach to the scientific focusing that identifies intangible benefits into contact with the natural environment, which speaks about the link between man and nature. In the second part, we will study the ways of approaching the artist to nature, citing the case study of the experiences of the artist and painter Silvia Viñao. Finally, we will complete the article exposing how ecological values are transmitted to the viewer through the artwork.

KEY WORDS: benefits of nature, arts, human development, ecology, values, landscape.

\footnotetext{
${ }^{1}$ María Mónica Rubio Vega: Bióloga por la Universidad de Navarra. Pamplona, España. Licenciada en Periodismo por la Universidad de Murcia. España.
} 


\section{Cómo citar el artículo:}

Rubio Vega, M. M., y Viñao Manzanera, S. (2016). Mejora personal e inspiración artística en el entorno natural. Revista de Ciencias de la Comunicación e Información, 21(1), 1-17.

doi: http://doi.org/10.35742/rcci.2016.21(1).1-17

\section{INTRODUCCIÓN}

En la mayoría de las sociedades occidentales se ha producido un alejamiento de la naturaleza. Cada vez más, el ser humano tiende a vivir en entornos urbanos que apenas dejan espacio para el contacto con elementos naturales. Si a ello le sumamos los horarios de una vida laboral trepidante y un estrés en aumento en el modo de vida, nos vemos en la necesidad de recordar los beneficios que ofrece el contacto directo con la naturaleza. Entre estos beneficios, los estudiosos se han referido a menudo al ámbito de la salud, pero cada vez más se estudian también los beneficios incluidos como emocionales, intelectuales o creativos.

Cuando los ciudadanos, inmersos en grandes urbes, realizan pequeñas incursiones en el medio natural, el contraste percibido es más evidente. Este hecho ha sido recogido en numerosos trabajos. En este capítulo se hace una mención a algunos estudios que reflejan cómo el entorno natural incide sobre la creatividad artística y se pone como ejemplo un caso práctico.

En la primera parte, nuestra investigación ahondará en los beneficios de la naturaleza para el individuo en general, y el modo en que el entorno natural mejora aspectos como el estrés, la frustración o las capacidades cognitivas. Entre estas capacidades cognitivas, en la segunda parte abordaremos de manera concreta la creatividad, exponiendo el caso práctico de la experiencia personal de una artista. Veremos cómo la naturaleza tiene la capacidad de influir no sólo en la creatividad del artista, sino también en la manera en que éste percibe su entorno, sensibilizándolo ante los valores ecologistas. Esto no solo influye en la forma de representar el paisaje, sino que el mensaje captado es transmitido posteriormente al espectador.

\section{OBJETIVOS}

Evidenciar la relación beneficiosa existente entre el ser humano y la naturaleza, demostrando la necesidad que siente el ser humano de relacionarse con un entorno natural.

Poner de manifiesto la urgencia de cuidar un entorno que es beneficioso para el ser humano.

Demostrar los beneficios concretos para el artista de la naturaleza como fuente de inspiración, y la repercusión que tiene el contacto con la naturaleza en la representación del paisaje actual.

Constatar mediante una experiencia concreta cómo la actual representación pictórica de la naturaleza refleja, en numerosas ocasiones, el deterioro 
medioambiental, haciendo llegar a su vez al espectador mensajes de carácter ecologista.

\section{METODOLOGÍA}

Con el fin de hacer más exhaustiva esta investigación hemos rehusado a ceñirnos al empleo de un solo tipo de metodología. Nuestros esfuerzos indagadores nos han llevado a explorar tanto la teoría como la práctica de un campo que consideramos apasionante; así pues, pasaremos a enunciar los distintos tipos de metodología empleada. En la primera parte del artículo se expone la fundamentación teórica, de índole cualitativa, recogiendo diversas investigaciones que exponen resultados tanto cualitativos como cuantitativos. En la segunda parte se expone un caso empírico que será relacionado con textos e imágenes históricas y su posterior análisis; de este modo se combinan la experiencia empírica con la metodología histórico-hermenéutica.

\section{RESULTADOS}

A continuación, expondremos el desarrollo y los resultados de esta investigación desplegando la recopilación de datos obtenida y las experiencias prácticas.

\subsection{Entorno natural y aportaciones beneficiosas para el individuo}

Los beneficios que proporciona la naturaleza al ser humano son de diversa índole y conocidos de antiguo. Así, tradicionalmente se han publicado numerosos trabajos que sirven para describir el que se puede denominar beneficio económico de la naturaleza, ya que ésta, efectivamente, provee al ser humano de alimento, agua, leña como fuente de energía, y de materias primas para su industria, y además regula el clima o las riadas, que tienen incidencia en este aspecto.

Posteriormente se comenzó a abordar el beneficio para la salud. En este campo se pueden incluir todos aquellos trabajos que profundizan en propiedades de la naturaleza como las de proporcionar oxígeno o limpiar el aire, y que tienen su máximo exponente en la construcción de sanatorios para tuberculosos en plena naturaleza, que nacen a principios del siglo XIX. Esta relación con el entorno natural aparece en el trabajo de Ruiloba sobre estos centros hospitalarios, donde destaca "La preocupación por la higiene y la funcionalidad, por la orientación soleada, la ventilación de las estancias, la vinculación con la naturaleza, etc., que los médicos exigían" (Ruiloba, 2011, p. 214), así como la afirmación de que "la ciudad sanatorial de Clairvivr, con capacidad para 55.000 habitantes, construida entre 1930 y 1933 en Salagnac, en Francia", se levantó con la idea de que en sus apartamentos "el enfermo pudiera disfrutar de toda la asepsia y beneficios terapéuticos de la naturaleza, en un ambiente familiar" (Ruiloba, 2011, p. 224); o cuando dice, de otro caso, que "La Ciudad Verde o Ciudad de Reposo de M. Ginzburg se basaba en el contacto del hombre con la naturaleza como medio para recuperar las fuerzas perdidas y conservar la salud" (Ruiloba, 2011, p. 229).

Así pues, Ruiloba reconoce estos "beneficios terapéuticos" de la naturaleza, lo que está en línea con una investigación muy popular de 1984, que también cabe recoger en este apartado. Se trata del conocido trabajo de Ulrich, en el que realizó un estudio 
sobre la recuperación de pacientes hospitalarios en igualdad de condiciones, salvo las vistas que ofrecían las ventanas de sus habitaciones, de modo que unos pacientes observaban directamente una pared de ladrillos mientras que otros podían contemplar el arbolado. Ulrich concluyó que "los pacientes con vistas de la ventana de árboles pasaron menos tiempo en el hospital que los que tenían vistas de la pared de ladrillo" (Ulrich, 1984, p. 1); y además de este postoperatorio más corto, "tomaron dosis menores de analgésicos moderados y fuertes, y tenían clasificaciones un poco más bajas de las complicaciones menores posquirúrgicas" (Ulrich, 1984, p. 2).

Por otra parte, muchas personas han experimentado en alguna ocasión a lo largo de su vida alguno de los distintos beneficios que proporciona el contacto con la naturaleza y que pueden englobarse en el campo de la salud en un sentido amplio, y aún más allá. Son esas sensaciones no solo de encontrarse físicamente bien, sino también de desconectar, de aclararse las ideas, y de hallar fuerzas emocionales, de reponerse espiritualmente...

Son beneficios relacionados con la mejora intelectual, la mejora emocional o el impulso de la creatividad. Son beneficios que de un tiempo a esta parte están siendo ampliamente investigados por diversos autores.

Contemplar a la naturaleza como un reservorio de beneficios para el desarrollo humano constituye un enfoque relativamente reciente dentro de los estudios que abordan los beneficios de la naturaleza, y su objetivo es, pues, tratar de identificar beneficios menos tangibles, que pueden agruparse dentro de los llamados inmateriales, intelectuales o espirituales.

Gran parte de estos estudios se despliegan a partir de la idea de que, precisamente, el ser humano residente en la gran mayoría de las sociedades calificadas como occidentales, occidentalizadas o desarrolladas, se está alejando del entorno natural en el que surgió, y si esto es así, lo que realmente ocurre es que se está alejando de la posibilidad de ser beneficiario de esos beneficios que otorga la naturaleza.

La población urbana, considerando como tal a la residente en los núcleos habitados con más de 20.000 almas, significa a comienzos del tercer milenio casi la mitad de los habitantes de la Tierra y las llamadas "megaciudades", urbes superiores a los diez millones de habitantes, superan la veintena, no faltan en ninguna parte del mundo y se han duplicado en número en las últimas décadas (J. Bosque Maurel, 1993-94), (Bosque, 2000, p. 36).

Según la página de Datos del Banco Mundial, en España, la población rural ha sufrido una disminución de un punto porcentual, desde constituir el $23 \%$ de la población total entre los años 1999 y 2008, al actual 22\%; y la población en aglomerados urbanos de más de un millón de personas, es decir, las áreas metropolitanas, en el año 2000 superaba el millón de habitantes.

En esta misma página, se recoge que:

Las ciudades pueden ser extremadamente eficientes. Es más fácil suministrar servicios de agua y saneamiento cuando las personas viven más concentradas 
en el espacio. También se facilita el acceso a salud, educación y otros servicios sociales y culturales. Sin embargo, a medida que las urbes crecen, aumenta el costo de satisfacer las necesidades básicas y se intensifica la presión sobre el medio ambiente y los recursos naturales (Banco Mundial).

$\mathrm{Y}$, de alguna manera, en las ciudades puede apreciarse esa necesidad de recuperar el contacto perdido con la naturaleza. Incluso donde mayor es la "presión" de la ciudad sobre el medio ambiente, más claramente se puede identificar esa mirada que el ser humano lanza hacia el entorno natural perdido. Ejemplo de ello son la multitud de anuncios que tienen como reclamo la naturaleza. Más de un lector se extrañaría si les aseguro que este paisaje se encuentra en la ciudad de Murcia:

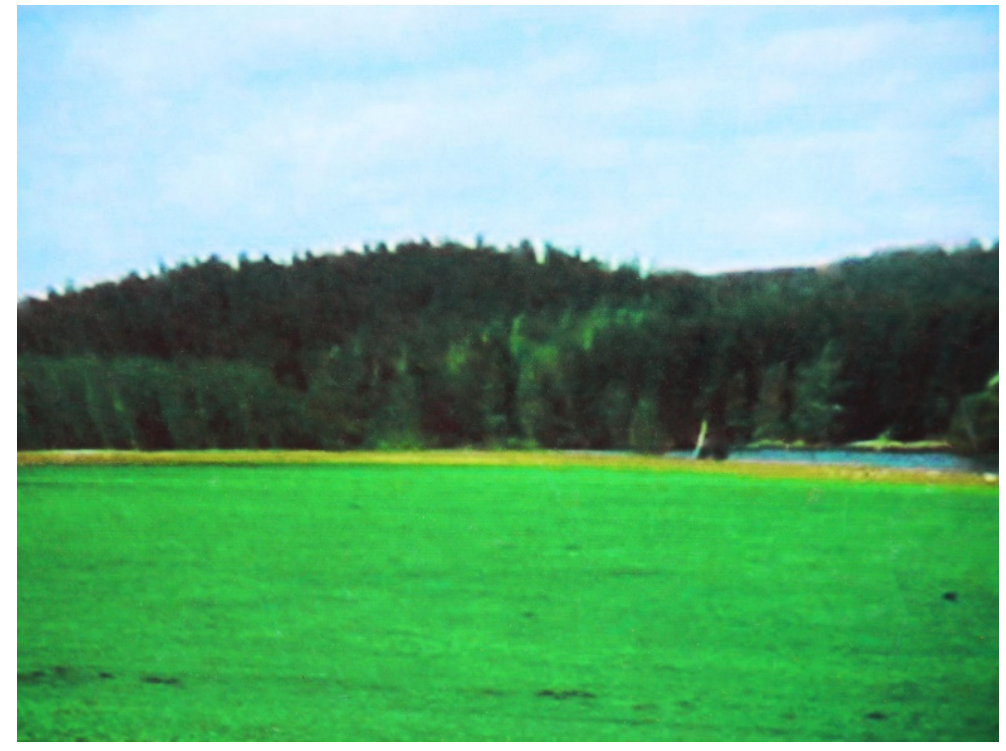

Figura 1. Paisaje. Mónica Rubio.

Y sin embargo, es cierto. Solo que no es un paisaje real, es una fotografía y se halla embelleciendo las paredes de un autolavado, en una gasolinera de la capital.

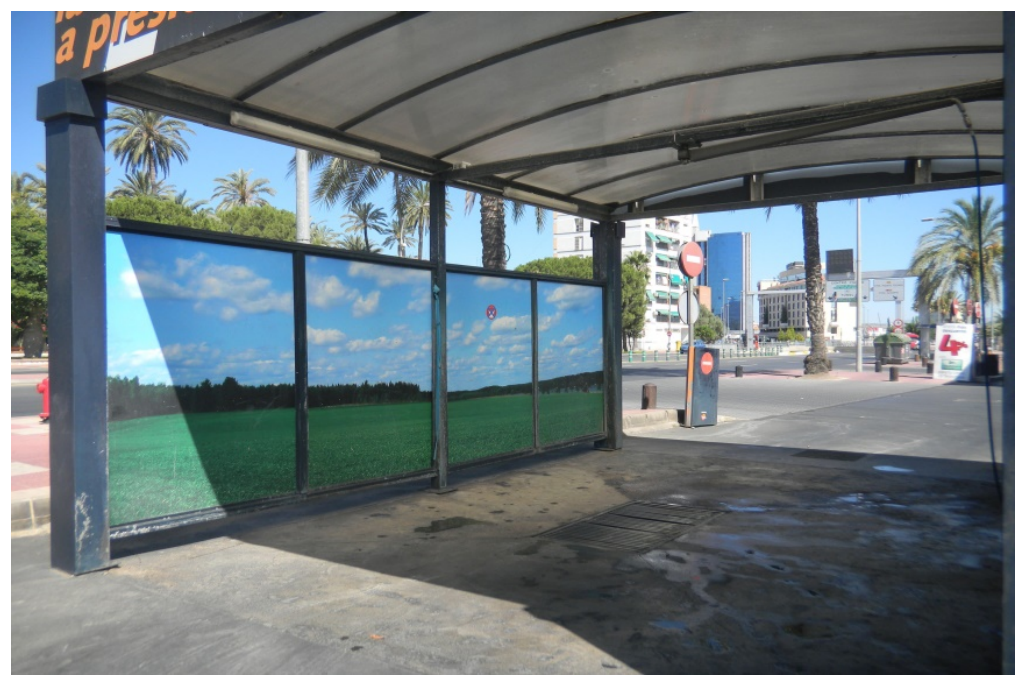

Figura 2. Autolavado. Mónica Rubio. 
Los propietarios del negocio seguramente no han leído los estudios realizados sobre la contemplación de la naturaleza y quizá no hayan oído nunca hablar de los beneficios del contacto con el entorno natural, pero de algún modo son conscientes de ello: saben que contemplar la naturaleza relaja, hace que la gente (cliente) se sienta más feliz, y saben que la gente feliz, consume más... Les habría resultado muy acertado conocer algunas de las investigaciones que pasamos a exponer aquí.

Por ejemplo, el trabajo del Dr. Mathew Blanco y su equipo, en el que realizaron un seguimiento de larga duración de los datos de la encuesta nacional de hogares del Reino Unido. Concluyeron que "las personas que vivían en las zonas más verdes reportaron menos angustia mental y una mayor satisfacción de la vida”. Además, aseguran que "Hemos encontrado que el vivir en una zona urbana con niveles relativamente altos de espacio verde puede tener un impacto significativamente positivo en el bienestar, más o menos igual a un tercio del impacto de estar casado" (Universidad de Exeter, centro de medios, 2013).

Igualmente, lan Alcock y su equipo defienden que "las zonas verdes de las ciudades podrían conducir a mejoras significativas y sostenidas de la salud mental de las personas que residen en sus proximidades", ya que han comprobado que "el cambio de residencia a una zona verde no sólo mejora la salud mental de las personas en un primer momento, sino que los beneficios sobre la salud se mantienen en el tiempo. [...] durante al menos 3 años después de mudarse" (lan Alcock, 2013).

Hay varias investigaciones dirigidas a indagar en la mejora intelectual. Es el caso de Wells, quien, tras un estudio con niños de un entorno urbano de bajos ingresos, encontró que los menores que viven cerca de áreas verdes muestran mejores habilidades cognitivas que los que no residen cerca de dichas zonas. Sus resultados, además, y en relación al punto anterior, "sugieren que el entorno natural puede desempeñar un papel en el bienestar de los niños dentro de un ambiente de vivienda mucho más importante del que ha sido reconocido previamente" $\mathrm{y}$, al respecto, la autora cree que "que el poder de la naturaleza es, de hecho, profundo" (Wells, 2000, pp. 790 y 791).

También ahondó en las posibilidades de obtener beneficios intelectuales de la naturaleza un equipo de investigadores en psicología ambiental de la Universidad Heriot-Watt y la Universidad de Edimburgo. En un trabajo titulado 'El cerebro urbano: análisis de la actividad física al aire libre con EEG móvil', realizaron un estudio para comprobar cómo un espacio 'verde', incluso en el entorno urbano, contribuye a mejoras de este tipo. Para ello, recurrieron a la electroencefalografía (EEG) móvil y analizaron grabaciones continuas de las señales relacionadas con la "emoción marcada (a corto plazo), la frustración, el compromiso, el entusiasmo a largo plazo (o excitación) y la meditación. Uno de los investigadores, el Dr. Roe, señaló después al New York Time que los ambientes naturales solicitan la atención del cerebro, pero se trata de una atención "sin esfuerzo. Se llama la atención involuntaria en psicología. Requiere nuestra atención, mientras que al mismo tiempo permite que haya lugar para la reflexión, y proporciona un descanso a las demandas atencionales continuas de las calles, típicas de la ciudad", afirmó, y sugirió que, a la hora de tomarse un descanso en el trabajo sería bueno "salir a caminar en un espacio verde o simplemente sentarse, o incluso ver los espacios verdes de la 
ventana de su oficina. [...] Es probable que tenga un efecto reparador y ayude con la fatiga de atención y recuperación del estrés" (Reynolds, G., 2013).

El aspecto más emocional también es foco de interés. Richard Louv expresa en su libro Volver a la Naturaleza su confianza en las posibilidades de reparación de la naturaleza sobre el individuo: "Para hallar la esperanza, sentido y alivio al dolor emocional [...] siempre tenemos a nuestra disposición el poder tonificante de la naturaleza", asegura (Louv, 2012, p. 81).

Al respecto, Corraliza mantiene que los niños son capaces de gestionar mejor su estrés si están en contacto con la naturaleza: "El impacto de los eventos estresantes en los niños es menor cuando la cantidad de naturaleza cercana es mayor, y este efecto positivo del contacto con el medio natural es más apreciable en aquellos niños que son más vulnerables", apunta; y defiende que:

La experiencia de vivir en un entorno natural puede amortiguar el efecto de algunos eventos estresantes. De aquí se deduce la importancia estratégica que tiene la inclusión de elementos naturales en los entornos residenciales y educativos. La salud y el bienestar también dependen de que estos entornos promuevan contactos frecuentes con elementos naturales (Corraliza, 2011, p. 226).

El paso, pues, que han dado estas nuevas investigaciones es focalizarse en esos otros beneficios más intangibles, pero de algún modo conocidos desde hace mucho tiempo, y pasar de la percepción a la demostración.

Como visión final y generalista del tema, se puede añadir aquí el trabajo de Europarc-España, perteneciente a Eurparc, la entidad paneuropea que engloba a organizaciones dedicadas a la conservación de la naturaleza. Europarc-España ha identificado una serie de beneficios que, sobre la salud mental y espiritual del individuo, tienen las áreas protegidas de España, pero que consideramos que pueden hacerse extensivos a los parajes naturales bien conservados, protegidos 0 no. Cabe señalar que la organización considera, a su vez, al primero de ellos como uno de los "beneficios más importantes de nuestras áreas protegidas para la salud", en general. Son los siguientes, que exponemos a continuación, y dos más que nos reservamos para el final:

- Aportan experiencias personales irrepetibles que promueven la mejora de la autoestima ya que muchas actividades suelen conllevar un plus de dificultad o suponen metas simbólicas [...]. Esta mejora de la autoestima se explica por la realización de una actividad de esfuerzo que logra la consecución de una meta que significa un premio. Esta consecución habitualmente se realiza en grupo, lo que refuerza los lazos de amistad y relación a la vez que favorece la solidaridad.

- Los numerosos elementos del patrimonio inmaterial que aportan las áreas protegidas contribuyen a la salud mental y espiritual del individuo. Son precisamente los valores del patrimonio inmaterial los que explican los vínculos identitarios, simbólicos y de pertenencia y arraigo al lugar de la población local, 
y los que explican la atracción y la satisfacción emocional de los que visitan las áreas protegidas

- La contemplación de la naturaleza ayuda a la recuperación de la fatiga mental, el estrés emocional, la depresión, la ansiedad y otros trastornos.

- La ausencia de ruido y el disfrute de un paisaje de calidad son claves para que la actividad física desarrollada multiplique los efectos beneficiosos de la liberación de endorfinas.

- Las actividades en las áreas protegidas permiten experimentar sensaciones pérdidas o muy disminuidas por la vida urbana: frío, calor, miedo, reconexión con los ritmos de la naturaleza. Esta última supone una oportunidad de conexión social entre el mundo rural y el urbano, aumentando la valoración de cosas menos materiales.

- Ofrecen la oportunidad para desarrollar la autonomía y el sentimiento de responsabilidad particularmente en la infancia y la pubertad.

- El contacto con formas de vida pasadas nos aportan sentido de la trascendencia del ser humano, nos ayudan a comprender cómo vivían nuestros ancestros y nos ayudan a establecer la conexión intergeneracional. (Múgica et al. 2013, p. 14).

Y, como hemos avanzado antes, del listado hemos extraído y apuntamos aquí aparte, por su relación con el presente trabajo, estos dos beneficios singulares: "Las áreas protegidas, especialmente las zonas más remotas e inaccesibles, ofrecen al individuo la posibilidad de experimentar la soledad y la quietud, aumentar la capacidad de reflexión e inspiración" y "Ofrecen la ocasión de salir de la rutina, favoreciendo la creatividad, la capacidad de fijar recuerdos al ser actividades poco habituales y la promoción de la inteligencia emocional del individuo" (Múgica et al., 2013, p. 14).

\subsection{Experiencias empíricas del artista en contacto con la naturaleza}

A continuación expondremos la experiencia personal de un artista que ha buscado durante años la inspiración en la naturaleza.

\subsubsection{La toma de conciencia de los valores ecológicos a través del contacto con la naturaleza}

Actualmente, ante los retos que nos plantean las sucesivas crisis o cambios que vivimos -crisis económica, crisis de valores, cambio climático-, y teniendo en cuenta que vivimos en un mundo cada vez más globalizado, debemos plantearnos el concepto de "valores" no solo como algo personal, sino como una cuestión personal e interpersonal. Es decir nuestros valores no solo guían nuestros actos, sino que repercuten directamente en los demás y en nuestro medio ambiente.

Los valores son modelos a seguir, parámetro de comportamiento. No se trata de un conjunto de normas que hay que cumplir, sino que son ideales o convicciones que seguimos de manera prácticamente automática una vez adquiridos.

Por este motivo, los valores no pueden transmitirse de forma únicamente teórica, ni se pueden imponer. Es decir, no tiene sentido obligar a una persona a cumplir unos valores, ya que entonces no hablaríamos de valores sino de normas. A menudo 
cuando se está educando a un menor, se le educa para seguir unas normas o pautas de comportamiento, pero si no se transmiten unos valores, una vez el niño o adolescente no está vigilado no cumplirá nada de lo que le han enseñado.

En el caso de la transmisión de los valores ecologistas o estéticos, lo más efectivo es procurar o provocar situaciones de aprendizaje. La enseñanza mediante la experiencia y la creación de situaciones de aprendizaje son métodos actualmente muy valorados por investigadores tan prestigiosos como Gardner (1994). En el caso de la transmisión de los valores ecológicos, se hace indispensable el contacto directo con la naturaleza, sin el cual no puede crearse un vínculo entre el ser humano y el entorno natural ¿Cómo puede gustar algo que no se ha experimentado? Algo muy parecido ocurre con el arte: ¿cómo puede interesar algo que nunca se ha visto?

\subsubsection{El paisaje pictórico como evocación de la naturaleza}

En numerosas épocas y lugares los artistas han buscado el contacto directo con la naturaleza para inspirarse o copiar la imagen percibida, y así lo han expresado innumerables teóricos tanto en Occidente como en Oriente. Escogeremos en este caso las palabras del pintor y teórico chino Kuo Hsi (1020-1090):

El que desee pintar estas obras maestras de la creación primero ha de sentirse cautivado por su encanto; después ha de estudiarlas con mucha diligencia; que vague por ellas; que sacie sus ojos en ellas; y que después ordene estas impresiones claramente en su mente. Entonces, con ojos que ignoren la seda y con manos sin conciencia de la tinta y el pincel, pintará esta maravillosa escena con una energía y una libertad sumas y la hará suya. (Racionero, 1997, p. 69).

Es más, estas reflexiones no se refieren solo a la labor del pintor, sino que cuando el pintor ha plasmado las sensaciones vividas en la naturaleza, éstas llegan al espectador:

A la visión de dichas montañas pintadas corresponden los similares estados de ánimo que se despiertan en el hombre. Es como si realmente se estuviera en esas montañas. Existen como si fueran reales y no pintadas. El vaho azulado y el sendero blanco excitan el deseo de caminar hacia allí; la caída del sol en un arroyo sereno hace sugerir el deseo de contemplarlo; (...) La contemplación de las buenas pinturas nutre estos deseos. Los lugares se hacen reales y el significado de estos cuadros es delicioso. (Racionero, 1997, p. 68).

Cuando la obra de arte es sincera, las sensaciones que el artista ha vivido son plasmadas de forma inconsciente en la obra de arte, y estas sensaciones son transmitidas al espectador. Una obra que transmita estas sensaciones, de algún modo está acercando al espectador no solo al arte sino también a la naturaleza. La persona que admira la grandiosidad de unas montañas en una pintura normalmente también la admira en la realidad.

Lo que conseguimos con la contemplación de la obra de arte es formar la sensibilidad, una facultad que no podemos formarla por medio de la memorización 
de textos y exámenes, sino mediante otros métodos. De este modo, el arte se convierte en una herramienta muy útil que llega donde otros recursos no consiguen hacerlo.

Además, el sistema también funciona en sentido contrario. Por ejemplo, la persona que tiene la sensibilidad de admirar los colores de una puesta de sol real, es más capaz de sentir admiración por una obra en la que aparezca una imagen de una puesta de sol al óleo, del mismo modo si te gustan las montañas es probable que te gusten los cuadros de montañas. Existe por tanto una necesidad de comprensión y conocimiento personal tanto del medio natural como del arte que lo refleja para el espectador, el educador, el educando o el artista.

\subsubsection{El artista inmerso en el entorno natural: experiencia práctica}

En este sentido, es esencial que si un artista quiere plasmar las sensaciones vividas en la naturaleza, debe mantener un contacto más o menos asiduo con esta. Este contacto puede producirse de varios modos. Para ejemplificarlo me basare en mi experiencia como artista.

En primer lugar, podemos citar el método más directo, que es pintar copiando directamente el paisaje en la naturaleza. La ventaja de este método reside en que podemos transmitir a la obra toda la inmediatez del momento, los colores y la luz reales de ese instante. Las sensaciones que sentimos en ese mismo momento son plasmadas directamente en la obra. Este método, bien empleado, confiere a la obra una gran vivacidad. Sin embargo, este modo de pintar tiene también los inconvenientes obvios de pintar en plena naturaleza; es decir, puede hacer viento, calor, frío, además de que con frecuencia suelen acudir insectos (figura 3 ).

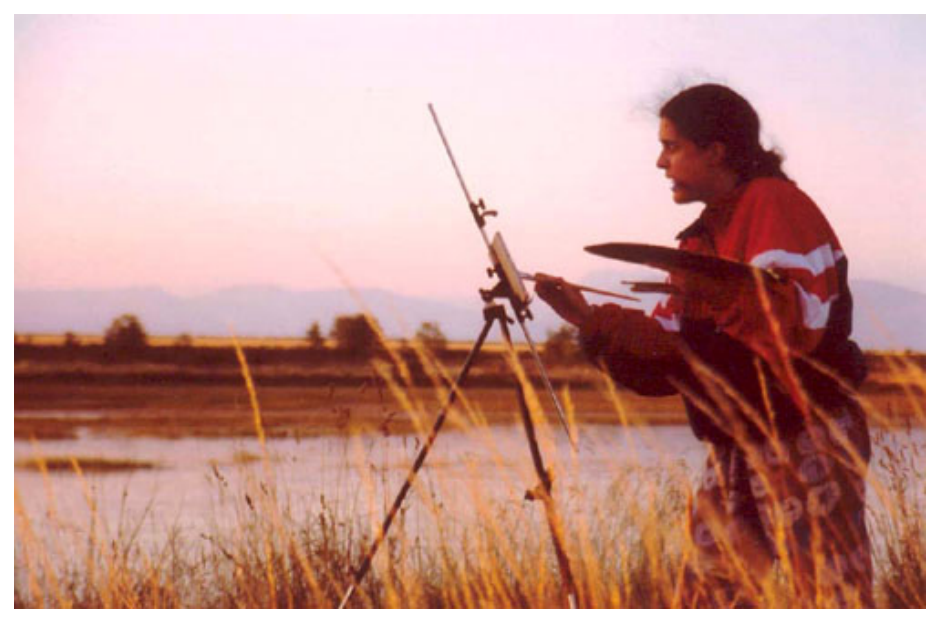

Figura 3. Pintando en la naturaleza. Fotografía: Luis Urbina.

En segundo lugar, puede tenerse un contacto directo con la naturaleza y luego plasmar las sensaciones vividas en la obra. Este método puede ser muy efectivo si el artista tiene memoria visual y si las sensaciones vividas perviven en la memoria. No obstante, para que pueda llevarse a cabo no debe transcurrir mucho tiempo entre el contacto con la naturaleza y la realización de la obra, pues las sensaciones vividas pueden desvanecerse. 
Por último, existe un término medio: tenemos también la posibilidad de coger apuntes en contacto directo con el medio natural y después basarnos en ellos para realizar una obra de mayor envergadura en la comodidad del estudio. Personalmente he recurrido a este método con bastante frecuencia en los últimos años empleando cuadernos de campo que permiten realizar dibujos o incluso acuarelas en la naturaleza (figura 4).

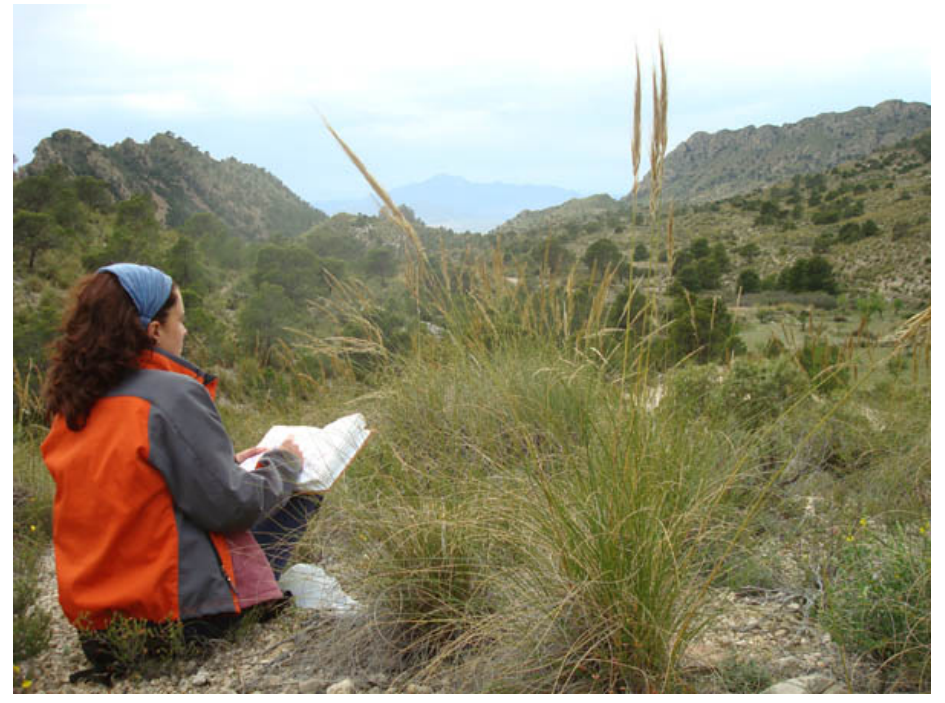

Figura 4. Tomando apuntes en la naturaleza. Fotografía: Luis Urbina.

Además, los cuadernos de campo ofrecen también la posibilidad de escribir anotaciones, sirven para guardar pequeños objetos como hojas o flores, así como de recordatorio y, una vez terminados, se convierten en una obra en sí mismos (figura 5).

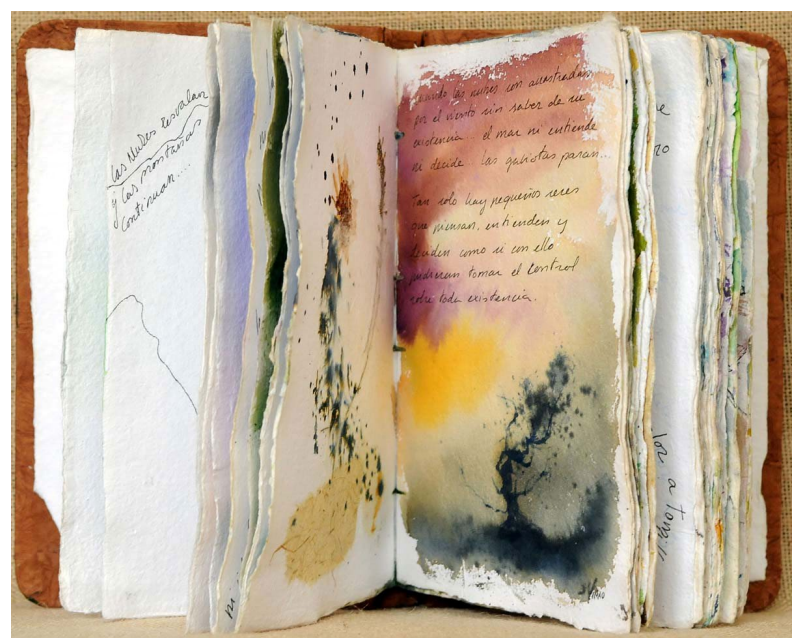

Figura 5. Cuaderno de campo, Silvia Viñao.

\subsubsection{El paisaje pictórico actual como transmisor de valores ecológicos}

Cuando cualquier persona que mantenga un contacto asiduo con la naturaleza toma conciencia del daño que estamos causando al medio ambiente, siente la necesidad de expresarlo. Si esa persona es artista puede hacerlo por medio de la obra de arte. 
4.2.3.1. La pequeñez del individuo inmerso en la grandiosidad de la naturaleza

En mi caso, una de las sensaciones más impactantes surgidas a raíz del contacto con la naturaleza es la sensación de la propia pequeñez frente a la grandiosidad de la misma. Esta sensación nos da otra visión del orden existencial. El ser humano es una pequeña figura que contempla la grandiosidad de la naturaleza; la admira y por tanto la respeta. Es frecuente, por tanto, que en mis paisajes aparezca una pequeña figura a la que llamo 'El Caminante', que pretende representar la pequeñez del ser humano frente a la grandiosidad de la naturaleza (figura 6).

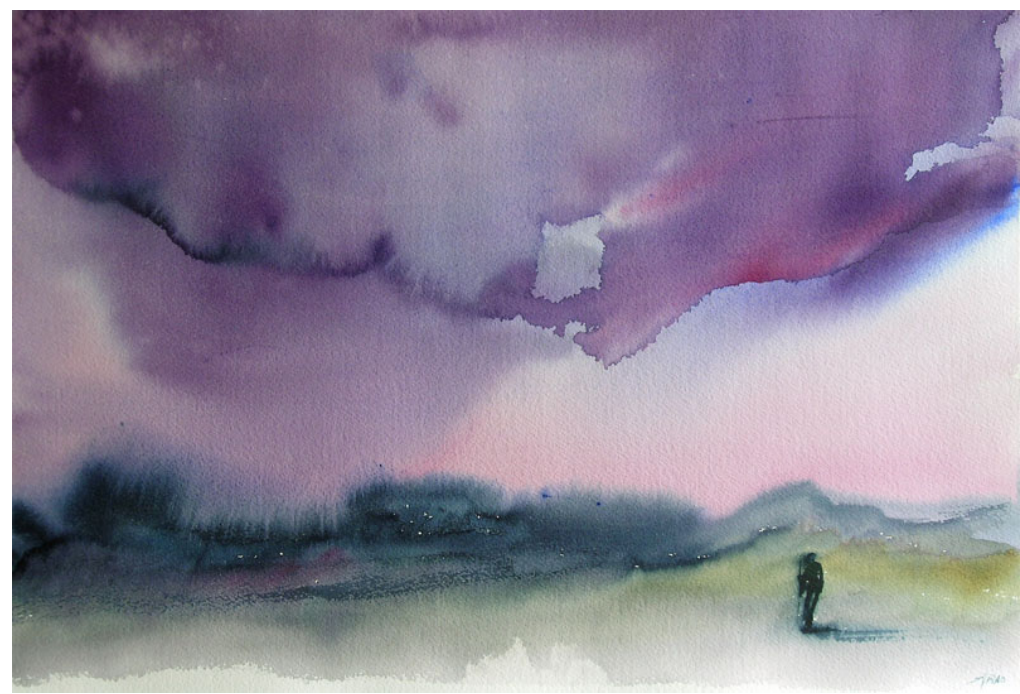

Figura 6. Caminando bajo el cielo. Silvia Viñao. Acuarela, 38x56cm, 2004.

Esta sensación ha sido representada en el arte en numerosas ocasiones por diversos artistas. El caso más conocido dentro de nuestra cultura es el de la obra titulada Monje junto al mar, de Friedrich (figura 7).

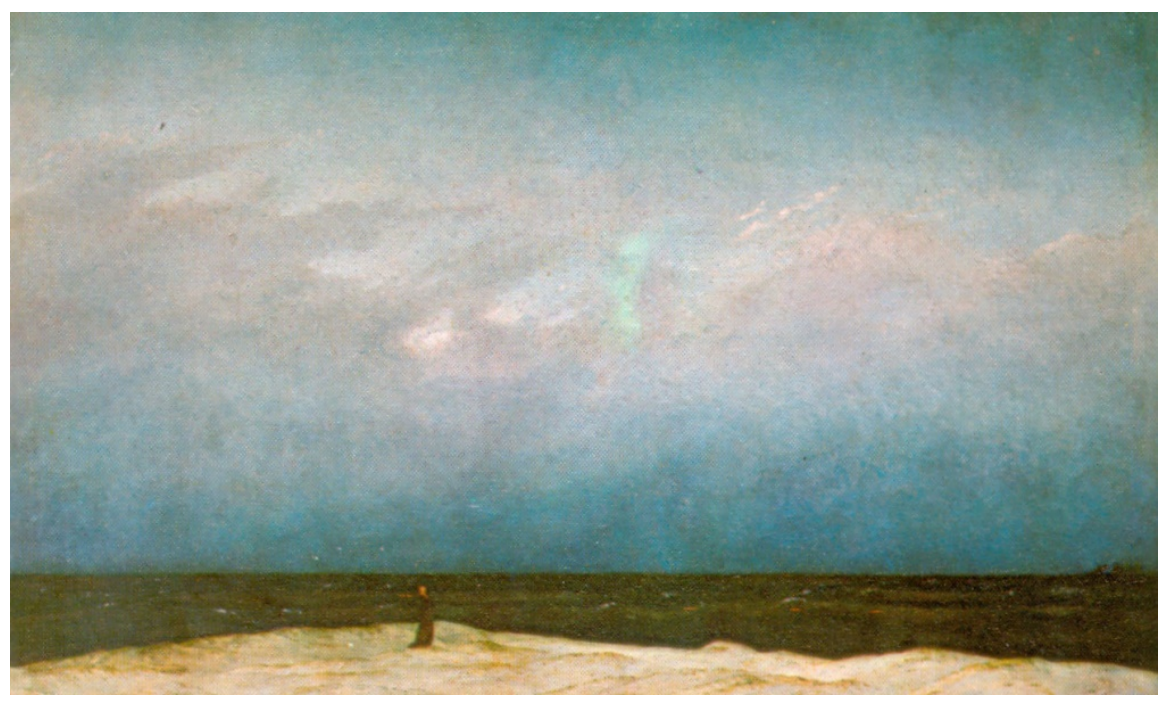

Figura 7. Monje junto al mar. Friedrich. Óleo, 1808-09. (Rauch, 2000, p. 433). 
Este cuadro ha suscitado muchas reflexiones de carácter existencial y espiritual. No es casualidad que la pequeña figura sea un monje. Friedrich pretende darle a la obra un carácter espiritual: en esa contemplación de la inmensidad de la naturaleza hay una contemplación de algo más grande que nosotros, algo que no sabemos explicar con palabras, pero que numerosos artistas han representado en sus obras.

En el Romanticismo la representación del paisaje no es una mera copia de una porción bella de la naturaleza, sino que está cargada de sentimientos. La sensación abrumadora que provoca la inmensidad de la naturaleza, o las fuerzas que la conforman, se convirtió en una fuente de inspiración para los artistas, dando lugar a la estética de lo sublime. Así pues, abundan los paisajes en los que se representan grandiosas montañas, inmensos cielos estrellados o fuertes tormentas.

Al otro lado del mundo, y sin conexión alguna, en la antigua China la filosofía taoísta tuvo tal auge entre los intelectuales que dio lugar a la llamada estética taoísta. El ideal de la filosofía taoísta es la comunión del ser humano con la naturaleza. Podríamos decir que se trata de una filosofía ecologista antes siquiera de que esta palabra fuera inventada.

Según la cosmología taoísta, el ser humano forma parte de la naturaleza, pero como un ser más. No somos los reyes de la creación, sino una pequeña parte de la naturaleza. Por esta razón, en la pintura tradicional china cuando se representa un paisaje es frecuente ver la figura del ser humano en pequeño frente a una naturaleza grandiosa y bellísima. Podemos contemplar un ejemplo un detalle de la obra de Hsia Kuei, (activo entre los años 1180-1230), (figura, 8).

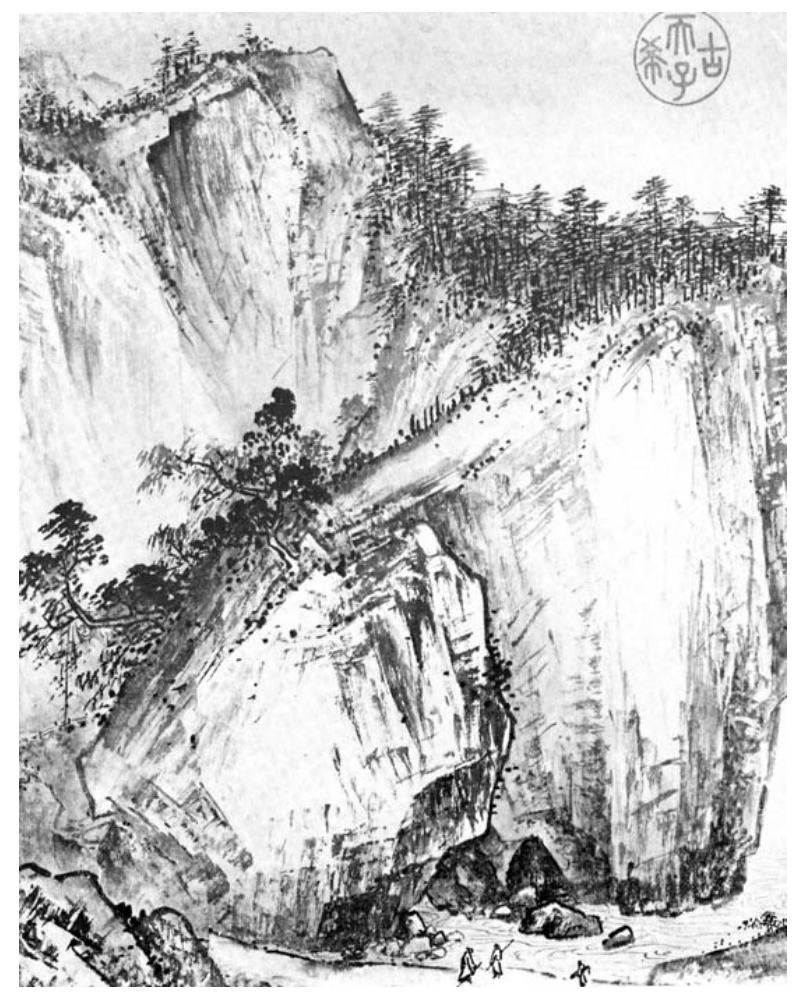

Figura 8. Vistas puras y remotas de colinas y arroyos (Detalle). Hsia Kuei.

(Tregear, 1991, 125). 
Cuando se tiene este concepto de la naturaleza y del lugar que el ser humano ocupa en ella, se está realizando un ejercicio de humildad: la naturaleza no nos pertenece, nosotros pertenecemos a ella. Si nos concebimos como un pequeño ser que pertenece a algo mucho mayor, ¿cómo podemos siquiera pensar en dañar esa entidad mayor a la que pertenecemos? Cuando las representaciones de la naturaleza son bellas también impulsan a admirarla y respetarla, y si el ser humano se representa absorto en la contemplación de la naturaleza se está transmitiendo el mensaje de la admiración y el respeto que esta impone.

4.2.3.2. El artista como observador y transmisor del deterioro del entorno natural

En la actualidad cualquier artista que decida pintar paisaje y que, por tanto, realice una observación de la naturaleza más o menos continuada, no tardará en observar el impacto de la intervención humana. Al caminar por el monte no es raro ver restos de basuras abandonados por excursionistas, árboles talados, incendios, vertidos, o sencillamente ver desaparecer zonas verdes enteras, por ejemplo, todo un paisaje costero allí donde se ha construido en esa zona una urbanización residencial.

Ante estas situaciones es cuando el artista actual, mínimamente sensible, no puede dejar de plasmar lo que está viendo. Como consecuencia, el paisaje pictórico inevitablemente se hace eco del desastre medioambiental que nos rodea. Para terminar, y volviendo a mi obra, pondré un ejemplo de estos hechos en situaciones experimentadas por mí misma.

En zonas del sur de España como Murcia y Almería, dos de los fenómenos más frecuentes son la desertización y la erosión. En mi región, Murcia, existen numerosas zonas desérticas que, aunque personalmente me parecen muy plásticas, no debían ir en aumento. A menudo, he comprobado también cómo en algunas zonas se talan o se queman árboles, y luego cuando llueve el agua arrastra toda la tierra. Esta situación se está agravando debido al cambio climático, pues cada vez hay periodos de sequía más largos y luego cuando llueve lo hace de forma torrencial, al no haber árboles el agua es arrastrada por la tierra produciéndose la erosión del suelo y de este modo la desertización va en aumento.

En mi acuarela Desertización (figura 9), he querido representar este fenómeno: la tierra aparece reseca, los matorrales están representados por grafismos muy agresivos ya que es un modo de reflejar el drama de la tierra mediante los elementos plásticos. En la parte superior de la imagen podemos ver las nubes descargando la lluvia de forma torrencial; cuando esto sucede sobre la tierra reseca y sin árboles se produce la erosión, de este modo, erosión y desertización van de la mano. 


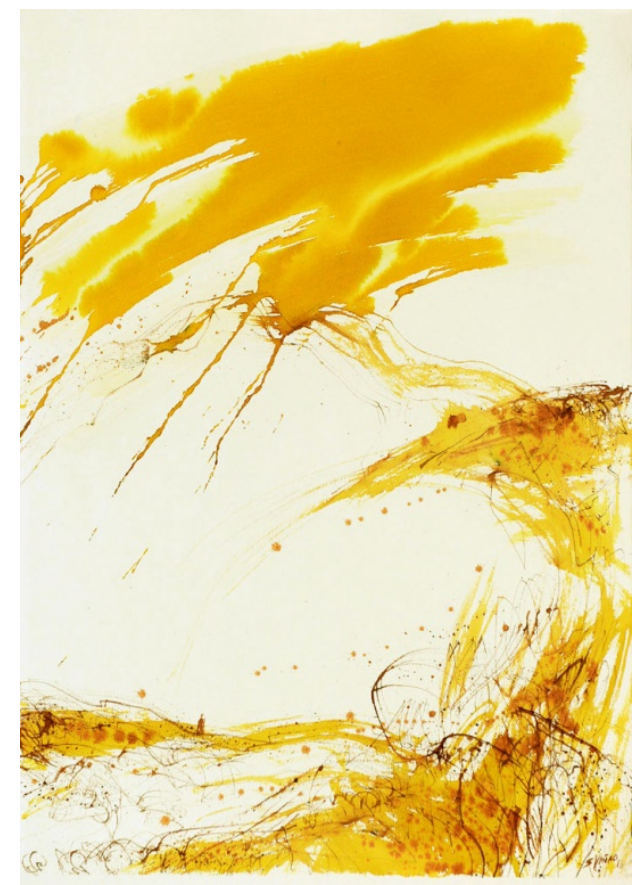

Figura 9. Desertización. Silvia Viñao. Acuarela, 48x34cm. 2013.

Como hemos podido comprobar, el contacto con la naturaleza no solo puede inspirar a los artistas con bellas imágenes, sino que también transmite mensajes ecologistas de tal modo que, cuando estos mensajes son plasmados en la obra, es muy posible que lleguen al espectador. No obstante, esta última faceta de la cadena artística suscita cierto debate, ya que además de que el arte siempre es algo subjetivo y depende mucho de la sensibilidad del espectador, otro problema hoy en día es que para que el mensaje llegue al espectador éste debe disponer de tiempo y al menos de un entorno adecuado para percibirlo, lo que es cada vez más difícil en un mundo tan lleno de prisas y ruidos.

Así pues, nos gustaría llamar la atención sobre el valor formativo y saludable tanto de la contemplación tanto de la naturaleza como del arte, ya que la sensibilidad es algo que se forma y que nos trasforma en seres cada vez más humanos, entendiendo el ser humano como alguien que forma parte de la naturaleza, más que del asfalto y los ruidos.

\section{CONCLUSIONES Y DISCUSIÓN}

Como ha quedado expuesto, la naturaleza ejerce un efecto beneficioso sobre el ser humano. Más aún cuando éste vive en grandes ciudades. Desde que el ser humano se apartó del entorno natural, que es su medio idóneo, los expertos han demostrado cómo la vuelta a la naturaleza repercute en numerosos aspectos tanto de su salud como de su estado de ánimo.

El ser humano busca la naturaleza en la ciudad y, al no encontrarla, la recrea en forma principalmente de anuncios visuales. Es habitual hallar referencias a ese entorno natural idílico que nos reconfortará y nos solucionará la vida -es decir, nos aportará beneficios- en multitud de soportes publicitarios y reclamos de empresas. 
Actualmente, los estudios que enfocan la naturaleza y sus beneficios están confluyendo en una mirada más global, apuntando a mejoras integrales para el ser humano, que finalmente redundan en un mejor desarrollo personal.

El contacto directo con el entorno natural beneficia también al artista como individuo pero, además, al tener éste una vocación artística y una mente más creativa, la naturaleza puede inspirarle especialmente si se propone desarrollar una obra en la que plasme paisaje.

La naturaleza influye en el artista transmitiéndole sensaciones que sería imposible sentir en un entorno urbano. Por ejemplo, por muchas imágenes bellas que veamos en un documental sobre la naturaleza, no podemos percibir el olor a romero y tomillo, o difícilmente podemos observar la lejanía del horizonte. El cerebro también capta estas sensaciones que, a su vez, estimulan la creatividad.

El estado emocional del artista se expresa a través de sus pinceladas. Como hemos visto, la naturaleza puede cambiar el estado emocional del individuo, por tanto, cuando el artista entra en contacto con la naturaleza, ésta le transmite unas sensaciones que son reflejadas en su obra. Como ejemplo, la sensación de inmensidad de la naturaleza frente a la pequeñez del ser humano ha sido captada por numerosos artistas en diferentes épocas y culturas.

El arte es una calle de doble sentido, y la obra de arte tiene una capacidad de transmisión de emociones y mensajes al espectador. Una imagen cala más directamente en la psique del espectador que la palabra; es más directa y llega de una forma más contundente a sus emociones, aunque también admitimos que existe un componente subjetivo.

El artista actual que busca inspirarse en el entorno natural a menudo encuentra una naturaleza diferente a sus antecesores, pues es frecuente hallar espacios naturales muy degradados. Si el artista tiene un mínimo de sensibilidad ante estos hechos, no dudará en plasmarlo en su obra, y a su vez ese mensaje será captado por el espectador. De este modo, no solo la naturaleza transforma al ser humano, sino también la obra de arte forma y transforma al individuo.

\section{REFERENCIAS}

\section{Libros:}

Gardner, H. (1994). Educación artística y desarrollo humano. Barcelona: Paidós.

Louv, R. (2012). Volver a la naturaleza. Barcelona: RBA.

Múgica, M., Muñoz, M., Puertas, B. (2013). Salud y áreas protegidas en España. Identificación de los beneficios de las áreas protegidas sobre la salud y el bienestar social. Oficina Técnica EUROPARC-España.

Racionero, L. (1997). Textos de estética taoísta. Madrid: Alianza editorial. 
Tregear, M. 1991. El arte chino. Barcelona: Ediciones destino.

Artículos en revistas:

Bosque-Maurel, J. (2000). Ciudad y Globalización, en Anales de Geografía de la Universidad Complutense, 20, 33-48.

Corraliza, A., y Collado, S. (2011). La naturaleza cercana como moderadora del estrés infantil, en Psicothema. 23(2), 221-226.

Granero-Gallegos, A. (2007). Las actividades físico-deportivas en la naturaleza y la industria turística, en Revista Internacional de Medicina y Ciencias de la Actividad Física y el Deporte, 7(26) 111-127. Recuperado de http://cdeporte.rediris.es/revista/revista26/artactnatural52.htm

lan Alcock et al. (2013). Longitudinal Effects on Mental Health of Moving to Greener and Less Green Urban Areas, en Environ. Sci. Technol., 48(2), 1247-1255. Recuperado de http://pubs.acs.org/action/doSearch?action=search\&searchText=alcock+white\& qsSearchArea=searchText\&type=within\&publication=40025991. Consultado el 2 de febrero de 2014.

Rauch, A. (2000). Neoclasicismo y romanticismo: la pintura europea entre dos revoluciones, en Toman, R. (Ed.) Neoclasicismo y romanticismo, pp. 318-479. Colonia: Könemann.

Reynolds, G. (2013). Easing brain fatigue with a walk in the park. En New York Times. Recuperado de https://well.blogs.nytimes.com/2013/03/27/easing-brainfatigue-with-a-walk-in-the-park/

Ruiloba Quecedo, C. (2011). La ciudad de la salud: los sanatorios antituberculosos. En Ciudades 14(1), 213-232.

Ulrich, R.S. 1984. View through a window may influence recovery from surgery, en American Association for the Advancement of Science. Posteriormente: Science 1984, v224 p420 (2).

Wells, N. M. (2000). At home with nature: Effects of 'Greenness' on Children's Cognitive Functioning, en Environment and Behavior, 32(6), 775-795.

$\underline{\text { Recursos electrónicos: }}$

Banco Mundial de Datos. Disponible en http://datos.bancomundial.org/indicador/SP.RUR.TOTL.ZS.

Universidad de Exeter. Central de Medios (2013). Green spaces may boost wellbeing for city dwellers. Recuperado de http://www.exeter.ac.uk/news/research/title 281065 en.html Consultado el 2 de febrero de 2014. 